\title{
Risk Factors for Recurrence of Radically Resected Mucinous Colorectal Adenocarcinoma
}

\author{
Qing Huang ${ }^{1, *}$ \\ Min-Hong Zou ${ }^{2, *}$ \\ Jian-Chang Wei ${ }^{1, *}$ \\ Ye Jiang ${ }^{3}$ \\ Zhuan-Peng Chen' \\ Qiang Wang' \\ Wang-Lin $\mathrm{Li}^{\prime}$ \\ Jie Cao (D)
}

'Department of Gastrointestinal Surgery, Guangzhou Digestive Disease Center, Guangzhou First People's Hospital, The Second Affiliated Hospital of South China University of Technology, Guangzhou, Guangdong, People's Republic of China; 2Department of Ultrasound, The Third Affiliated Hospital, Sun Yat-Sen

University, Guangzhou, People's Republic of China; ${ }^{3}$ Department of Pathology, The Third Affiliated Hospital, Sun Yat-Sen University, Guangzhou, People's Republic of China

*These authors contributed equally to this work
Background: Mucinous adenocarcinoma (MA) is a subtype of colorectal cancer (CRC) associated with a higher incidence of local extension and worse survival compared to nonmucinous adenocarcinoma, but few studies have investigated surgery-related predictors for recurrence of MA. Therefore, we aimed to elucidate the predictors for local recurrence and remote metastasis of MA after surgery.

Patients and Methods: This study retrospectively analyzed 162 patients with mucinous colorectal adenocarcinoma (MAC) after radical resection. Analysis variables included demographics, clinical indicators, pathologic stage, surgical procedure, adjuvant therapy, and recurrence. Univariate and multivariate analyses were performed to investigate the risk factors for local and distant tumor relapse.

Results: A total of 162 patients (86 male) with a mean age of 58.26 years were included; $70.37 \%$ of patients had colonic tumors, and $29.63 \%$ had rectal tumors. The 5-year diseasefree survival (DFS) rates for these patients were as follows: $100 \%$ for TNM stage I, $71.2 \%$ for stage II, and $47.8 \%$ for stage III. Five-year DFS rates of MAC, colonic and rectal MA were $62.0 \%, 65.8 \%$, and $51.7 \%$, respectively. Local recurrence occurred in 38 patients and distant metastasis in 33 patients. In univariate analysis, predictors for local recurrence of MAC were intraoperative blood loss, intraoperative transfusion, and N2 stage; and predictors for distant metastasis were male sex, CA199, CEA, intraoperative blood loss, T4 stage, and $\mathrm{N} 2$ stage. In multivariate analysis, predictors for local recurrence of MAC were intraoperative transfusion $(P=0.04, O R=4.175)$ and $\mathrm{N} 2$ stage $(P=0.000, O R=5.291)$, and predictors for distant metastasis were male sex $(P=0.049, O R=2.410), \mathrm{CA} 199(P=0.02, O R=1.003)$, and T4 stage $(P=0.007, O R=4.006)$.

Conclusion: Intraoperative transfusion and N2 stage were significant predictors for local recurrence. Male sex, CA199, and T4 stage were significant predictors for distant metastasis. Knowledge of the risk factors for postoperative recurrence provides a basis for logical approaches to treatment and follow-up of MAC.

Keywords: colorectal cancer, mucinous adenocarcinoma, local and distant recurrence

\section{Introduction}

Colorectal cancer (CRC), the third most diagnosed cancer and the second leading cause of cancer-related deaths, is a malignant tumor with a high prevalence: an estimated 1.9 million people develop CRC worldwide every year. ${ }^{1,2}$ Mucinous colorectal adenocarcinoma (MAC) is a special type of CRC with distinct pathological features. MAC tumors are composed of more than $50 \%$ extracellular mucin produced by tumor acinar cells. ${ }^{3}$ Cases of MAC account for $1.6-25.4 \%$ of primary CRC. Large population-based studies of the prevalence of CRC have shown lower 
rates (4-5\%) of MAC among Asians with CRC. ${ }^{4-6}$ Given the rarity of the disease, relatively little is known about the best approaches to treatment and the prognosis of MAC.

Compared with non-mucinous adenocarcinoma, MAC is more frequently found in female and younger patients, ${ }^{7}$ and has a worse prognosis. ${ }^{8-11}$ The worse prognosis of MAC may be due to its diagnosis at more advanced stages, its greater propensity for early spread to regional lymph nodes and peritoneal implants, and its resistance to chemotherapy. MAC is considered poorly differentiated (grade 3) according to the WHO tumor grade criteria based on the extent of glandular formation. Guidelines for $\mathrm{CRC}$ indicate that $\mathrm{MAC}$ is a risk factor for $\mathrm{CRC}$; for example, surgical resection with lymph node dissection is recommended for additional treatment after endoscopic resection of pT1 CRC when mucinous adenocarcinoma (MA) is observed. ${ }^{12}$ Adjuvant chemotherapy is recommended for patients with stage II CRC with poor histological differentiation (grade 3-4) accompanied by MMRproficient or microsatellite stable tumors. ${ }^{13}$ However, there are still no current guidelines for the treatment of MAC, even though individualized and precise treatment is critical for cancer therapy. We and others believe that specialized, precision therapy is needed for MAC. ${ }^{14}$ Thus, it is of significant clinical importance to investigate MAC.

In previous reports, the distinctive clinicopathologic features of MAC and their implication on the therapeutic strategy and prognosis were investigated. However, there are few studies that have conducted analyses of surgeryrelated risk factors. Local recurrence and distant metastasis are major challenges to overcome in order to improve the survival of patients with CRC after surgery. Therefore, this retrospective study aimed to elucidate clinical, pathologic, and surgery-related risk factors for local and distant relapse of MAC after surgical resection.

\section{Materials and Methods}

\section{Patients}

All CRC patients enrolled in this study were treated at the Third Affiliated Hospital of Sun Yat-Sen University and Guangzhou First People's Hospital from 2009 to 2018. Local Institutional Review Boards (IRB) approved the data acquisition, this study was conducted in accordance with the Declaration of Helsinki. The data included demographics, clinical indicators, pathologic stage, surgical procedure, adjuvant therapy, and recurrence. All patients were staged according to the AJCC 6th or 7th edition manual for CRC. ${ }^{15,16}$

Inclusion criteria were as follows: (1) the diagnosis of MAC was confirmed pathologically; (2) patients undergoing radical surgery. Exclusion criteria were as follows: (1) patients presented with peritoneal or distant metastases (M1 stage) at diagnosis; (2) multiple primary tumors of the colorectum; (3) palliative resection; (4) patients who were lost during follow-up or whose data were missed.

\section{Surgical Technique, Histopathological Examination, Postoperative Adjuvant Chemotherapy and Follow-Up}

All surgeries were performed by qualified, experienced colorectal surgeons. All operations assisted were radical resections with a complete mesocolic excision $(\mathrm{CME})^{17}$ or total mesorectal excision (TME), ${ }^{18}$ which were performed according to protocol guidelines. All resected specimens were examined and confirmed by pathologists and surgeons shortly after surgery. MAC is a histological subtype of colorectal cancer which is typically characterized by pools of extracellular mucin containing malignant epithelium. The TNM classification was defined by the criteria of the 6th or 7 th edition manual of the AJCC/UICC. Postoperative adjuvant chemotherapy was recommended for patients with TNM high-risk stage II and III disease, unless the patient's physical status was unsuitable for chemotherapy administration or a patient was unwilling to receive chemotherapy. These patients received first-line chemotherapy based on 5-FU or capecitabine according to the National Comprehensive Cancer Network (NCCN) guidelines at the time. The Follow-up is according to NCCN guideline for colon cancer and rectal cancer (To view the most recent version of these guidelines, visit NCCN.org).

\section{Observation Indexes}

Preoperative indexes included age, gender, comorbidity, American Society of Anesthesiology (ASA) score, tumor location, and the tumor markers carbohydrate antigen 199 (CA199) and carcinoembryonic antigen (CEA). The intraoperative indexes included operation time, intraoperative blood loss, blood transfusion, combined organ resection, postoperative complications, and number of lymph nodes harvested. Postoperative indexes included tumor size, pathological $\mathrm{T}$ stage, $\mathrm{N}$ stage, tumor grade (TNM), positive lymph numbers, and postoperative complications. 
The follow-up indexes included adjuvant chemotherapy received, disease-free survival (DFS), local recurrence, and distant metastasis. For DFS, the follow-up time was recorded from the date of surgery to the first recurrence date. The classifications of local recurrence and distant metastasis were based on where the recurrence was first found by colonoscopy, CT, MRI, or PET-CT. ${ }^{19}$

\section{Statistical Analyses}

All statistical analyses were performed using IBM SPSS26 (IBM Corp). Quantitative data are expressed as mean \pm standard deviation (SD) or median. Survival curves for DFS data were constructed using Kaplan-Meier method, and the curves were compared by the Log rank test. Significant prognostic factors identified using univariate analysis were further evaluated by logistic regression analysis. When the P-value was less than 0.05 in univariate analysis, it would be included in the multivariate analysis. Multivariate analysis was performed using an enter method. A P-value $<0.05$ was considered statistically significant.

\section{Results \\ Demographics}

During the period from 2009 to 2018 , we collected a total of $162 \mathrm{MAC}$ cases according to a pathological database from 4527 cases of CRC at the Guangzhou First People's Hospital and the Third Affiliated Hospital of Sun Yat-Sen University. There were 60 cases with relapse $(27$ cases with local recurrences, 22 cases with distant metastases, and 11 cases with both) (Figure 1).

Patients included a total of 76 men (46.91\%) and 86 women $(53.09 \%)$ with a median age of 60 years (range, 15-87). There were 69 patients $(42.59 \%)$ with right colonic MA, 45 patients $(27.78 \%)$ with left colonic MA, and $48(29.63 \%)$ with rectal MA. Most patients (114, 70.37\%) received adjuvant chemotherapy. Most MAC cases $(93.8 \%$ of colonic tumors and $87.5 \%$ of rectal tumors) were T3-T4 stage. According to the TNM classification by ACJJ, there were $6.79 \%$ at stage $I(n=11), 40.12 \%$ at stage II $(n=65)$, and $53.09 \%$ at stage III $(n=86)$ (Table 1$)$.

The mean follow-up time for the endpoint of relapse free period (RFP) was 4 years (range 0-11), and the study

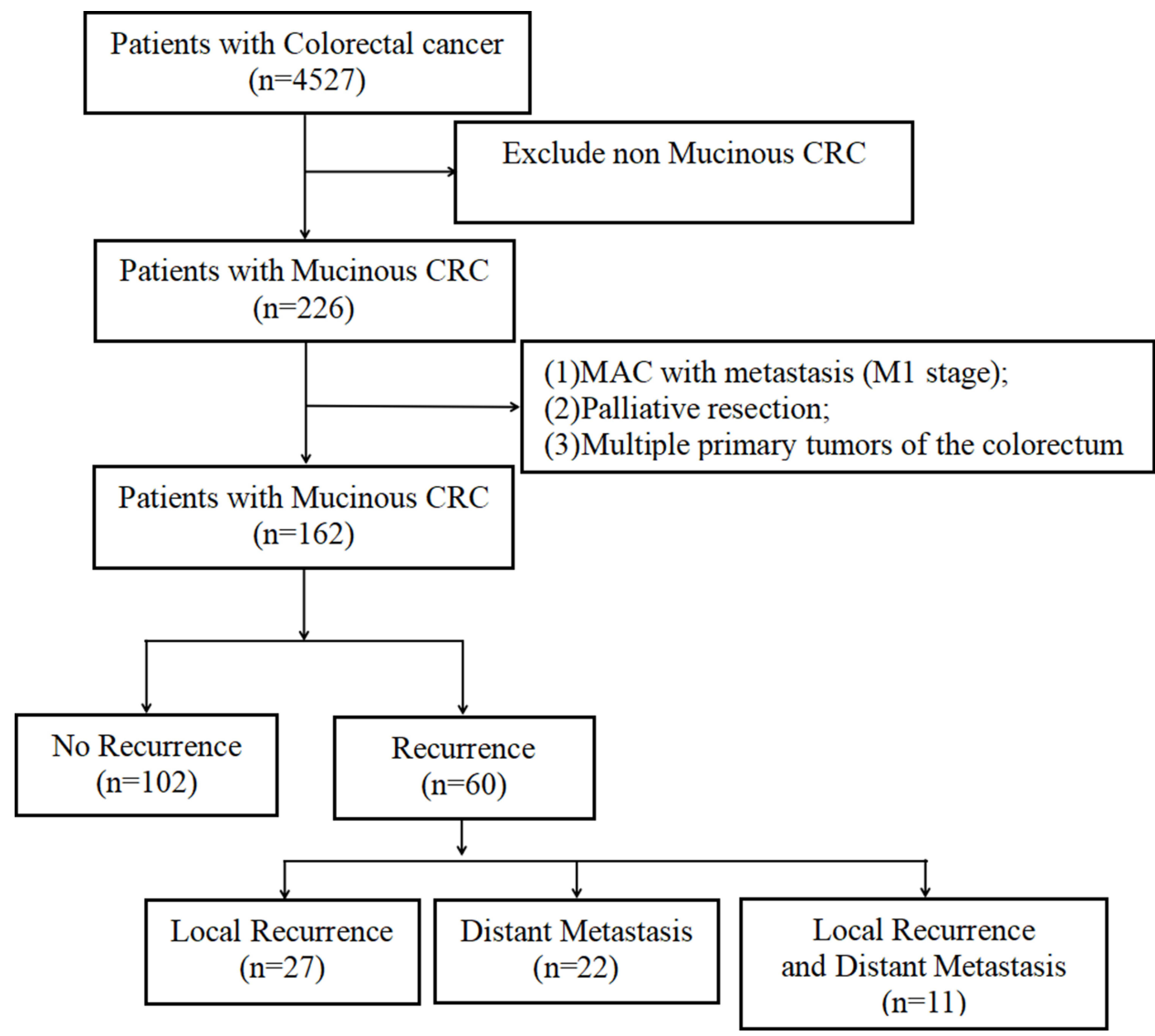

Figure I Flow diagram showing patient selection and exclusion process. 
Table I Clinical and Pathologic Information of I62 MAC

\begin{tabular}{|c|c|c|}
\hline \multicolumn{3}{|c|}{ Clinical and Pathologic Information } \\
\hline Age & Median (range) & $60(15-87)$ \\
\hline Gender & Male/Female & $76 / 86$ \\
\hline Comorbidities & Yes/No & $61 / 101$ \\
\hline ASA score & $\mathrm{I} / \mathrm{II} / \mathrm{III}$ & $73 / 68 / 21$ \\
\hline Tumor location & Right/Left/Rectal & $69 / 45 / 48$ \\
\hline Tumor size $(\mathrm{cm})$ & Mean \pm SD & $4.4 \pm 12.1$ \\
\hline CAI99 (U/mL) & Mean \pm SD & $57.5 \pm 152.6$ \\
\hline CEA (ng/mL) & Mean \pm SD & $16 \pm 42.1$ \\
\hline Adjuvant chemotherapy & Yes/No & $114 / 48$ \\
\hline Number of LNs & Median (range) & $17(5-53)$ \\
\hline T stage & $\mathrm{TI} / \mathrm{T} 2 / \mathrm{T} 3 / \mathrm{T} 4$ & $\mathrm{I} / \mathrm{I} 2 / 74 / 75$ \\
\hline$N$ stage & $\mathrm{N} 0 / \mathrm{N} I / \mathrm{N} 2$ & $76 / 36 / 50$ \\
\hline TNM stage & I/II/III & $\mathrm{II} / 65 / 86$ \\
\hline
\end{tabular}

Abbreviations: ASA, American Society of Anesthesiology; CA199, carbohydrate antigen 199; CEA, carcinoembryonic antigen; LN, lymph node; SD, standard deviation.

endpoints were local recurrence or distant metastasis of the disease. The pattern of local recurrence was as follows: recurrent abdominal or pelvic masses $(n=13,8.02 \%)$, peritoneal dissemination $(\mathrm{n}=12,7.41 \%)$, recurrent enlarged LNs ( $\mathrm{n}=5,3.09 \%)$, and recurrent masses with peritoneal nodules $(\mathrm{n}=8,4.94 \%)$. The distant metastases included isolated liver metastasis $(\mathrm{n}=13,8.02 \%)$, lung metastasis $(\mathrm{n}=8,4.94 \%)$, bone metastasis $(\mathrm{n}=6,3.7 \%)$, brain metastasis $(\mathrm{n}=1,0.62 \%)$, liver with lung metastasis $(\mathrm{n}=4$, $2.47 \%$ ), and liver with bone and brain metastasis $(n=1$, $0.62 \%$ ) (Table 2).

\section{The 5-Year Disease-Free Survival of MAC}

The Kaplan-Meier plot showed that the 5-year DFS rates of MAC, colonic MA, and rectal MA were $62.0 \%, 65.8 \%$, and $51.7 \%$, respectively. There were no significant differences among these three groups ( $P=0.504$, Figure $2 \mathrm{~A})$. Five-year disease-free Survival (DFS) rates of patients were as follows: $100 \%$ for TNM stage I, $71.2 \%$ for TNM stage II, and $47.81 \%$ for TNM stage III. There were significant differences among these three groups $(P=0.001)$ (Figure 2B).

\section{Univariate Analysis of the Predictive Factors}

Univariate analysis showed that the predictive factors for local recurrence of MAC were intraoperative blood loss $(P=0.004, O R=1.005)$, intraoperative transfusion $(P=0.002, \quad O R=5.179) \quad$ and $\quad \mathrm{N} 2$ stage $(P=0.000$, $O R=4.643$ ) (Table 3). Subgroup analysis showed that
Table 2 Surgical and Prognosis Outcome of 162 MAC

\begin{tabular}{|c|c|c|}
\hline \multicolumn{3}{|c|}{ Surgical and Prognosis Outcome } \\
\hline Surgical method & LAP/OPEN & $83 / 79$ \\
\hline $\begin{array}{l}\text { Operative time } \\
(\mathrm{min})\end{array}$ & Mean \pm SD & $211 \pm 78.3$ \\
\hline Blood loss (mL) & Mean \pm SD & $130.7 \pm 108.3$ \\
\hline $\begin{array}{l}\text { Multivisceral } \\
\text { resection }\end{array}$ & $\begin{array}{c}\text { Total (\%) } \\
\text { Abdominal wall (\%) } \\
\text { Small bowel (except } \\
\text { duodenum) (\%) } \\
\text { Urinary organs (\%) } \\
\text { Gynecologic organs (\%) } \\
\text { Gallbladder (\%) }\end{array}$ & $\begin{array}{l}14(8.64) \\
2(1.23) \\
5(3.09) \\
1(0.62) \\
3(1.85) \\
3(1.85)\end{array}$ \\
\hline $\begin{array}{l}\text { Postoperative } \\
\text { complication }\end{array}$ & Total (\%) & $26(16.05)$ \\
\hline $\begin{array}{l}\text { The frequency of } \\
\text { appearance }\end{array}$ & $\begin{array}{c}\text { Anastomotic Hemorrhage (\%) } \\
\text { Intraabdominal bleeding (\%) } \\
\text { Leakage (\%) } \\
\text { Gastroplegia (\%) } \\
\text { Infection (incision and } \\
\text { abdomen) (\%) } \\
\text { Pulmonary infection (\%) } \\
\text { Obstruction (\%) } \\
\text { Renal insufficiency (\%) }\end{array}$ & $\begin{array}{l}3(1.85) \\
2(1.23) \\
5(3.09) \\
2(1.23) \\
12(7.4 I) \\
6(3.7) \\
9(5.56) \\
1(0.62)\end{array}$ \\
\hline Local recurrence & $\begin{array}{c}\text { Total (\%) } \\
\text { Recurrent abdominal or pelvic } \\
\text { masses (\%) } \\
\text { Peritoneal dissemination (\%) } \\
\text { Recurrent enlarged LNs (\%) } \\
\text { Recurrent masses and } \\
\text { Peritoneal nodules (\%) }\end{array}$ & $\begin{array}{c}38(23.46) \\
13(8.02) \\
12(7.41) \\
5(3.09) \\
8(4.94)\end{array}$ \\
\hline Distant metastasis & $\begin{array}{c}\text { Total (\%) } \\
\text { Liver metastasis (\%) } \\
\text { Lung metastasis (\%) } \\
\text { Bone metastasis (\%) } \\
\text { Liver and Lung metastasis (\%) } \\
\text { Liver, Bone and Brain } \\
\text { metastasis (\%) } \\
\text { Brain metastasis (\%) }\end{array}$ & $\begin{array}{c}33(20.37) \\
13(8.02) \\
8(4.94) \\
6(3.7) \\
4(2.47) \\
1(0.62) \\
1(0.62)\end{array}$ \\
\hline
\end{tabular}

Abbreviations: LAP, laparoscopic surgery group; OPEN, open surgery group; LN, lymph node; ${ }^{a}$ some patients have multiple postoperative complications.

the predictors for local recurrence of colonic MA were intraoperative blood loss $(P=0.008, O R=1.006)$, intraoperative transfusion $(P=0.043, O R=3.952), \mathrm{N} 2$ stage $(P=0.004, \quad O R=5.044)$ and T4 stage $(P=0.029$, $O R=3.752$ ) (Table 4). The main predictor for local recurrence of rectal MA was intraoperative transfusion ( $P=0.014, O R=7.857)$ (Table 5). 

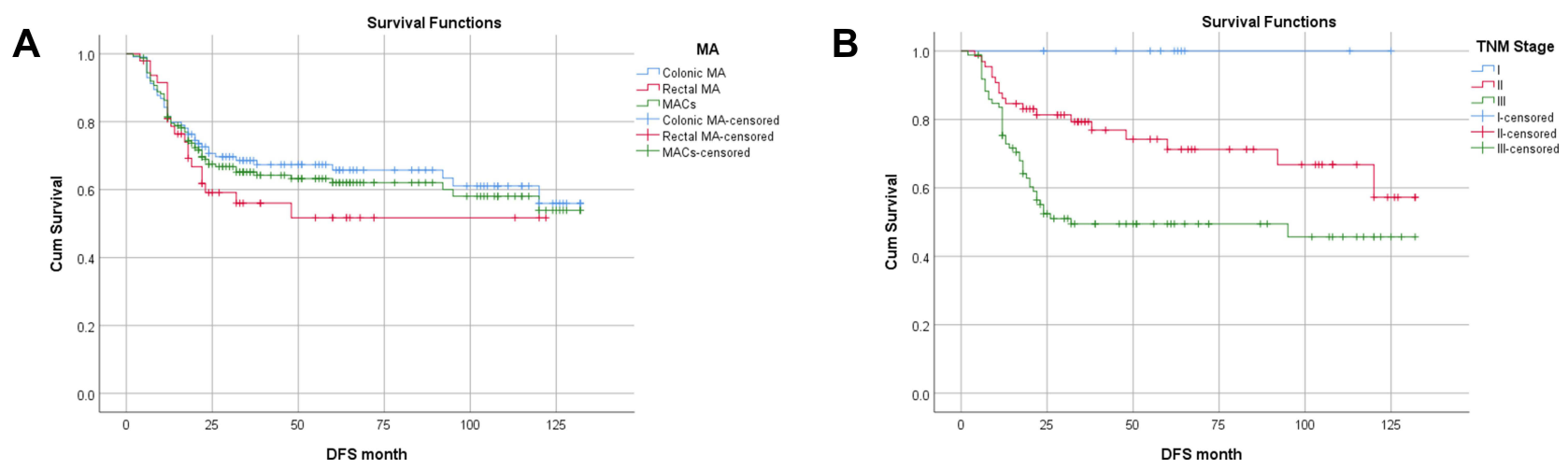

Figure 2 (A) Log Rank (Mantel-Cox) test=1.37I, $P=0.504$. Five-year DFS rates of MAC, colonic MA, and rectal MA were $62.0 \%, 65.8 \%$, and $51.7 \%$, respectively. Figure 2 (B) Log Rank (Mantel-Cox) test $=14.290, P=0.00$ I. Five-year DFS rates of TNM stage I, TNM stage II, and TNM stage III were $100 \%, 71.2 \%$, and $47.81 \%$, respectively.

Using univariate analysis, we found that the predictive factors for distant metastasis of MAC were male sex $(P=0.035, \quad O R=2.410), \quad$ CA199 $\quad(P=0.011, O R=1.004)$, CEA $(P=0.020, O R=1.010)$, intraoperative blood loss $(P=0.022, O R=1.004)$, T4 stage $(P=0.007, O R=4.125)$, and N2 stage $(P=0.018, O R=3.4)$ (Table 6). Subgroup analysis of the predictors for distant metastasis of colonic MA and rectal MA revealed that CA199 $(P=0.022$, $O R=1.003), \quad$ CEA $\quad(P=0.004, \quad O R=1.017), \quad$ T4 stage $(P=0.022, O R=4.628)$, N2 stage $(P=0.006, O R=6.568)$, and TNM stage III $(P=0.019, O R=5.308)$ were predictors for distant metastasis of colonic MA (Table 7), and CA199 $(P=0.050, \quad O R=1.013)$ and intraoperative blood loss $(P=0.027, O R=1.007)$ were predictors for local recurrence of rectal MA (Table 8).

\section{Multivariate Analysis of the Independent Predictors}

Using multivariate analysis, we found that the independent predictors for local recurrence of MAC were intraoperative transfusion $(P=0.04, O R=4.175)$ and $\mathrm{N} 2$ stage $(P=0.000, O R=5.291)$ (Table 9). The Hosmer-Lemeshow test had a $P$ value of 0.00 , indicating good fit of the data to the model. The AUC of the model was $0.771(95 \% \mathrm{CI}$ : 0.688-0.855) with standard error of 0.43. Calibration Plot showed that the model expected curve was close to the observed curve, indicating that the model has good predictive capabilities (Supplemental Figure 1A). Subgroup analysis showed that the independent predictor for local recurrence of colonic MA was N2 stage $(P=0.028$, $O R=3.592$ ) (Table 10). The independent predictor for local recurrence of rectal MA was intraoperative transfusion $(P=0.014, O R=7.857)$ (Table 11). Overall, the independent predictors of distant metastasis of MAC were male sex $\quad(P=0.049, \quad O R=2.410), \quad$ CA199 $\quad(P=0.02$, $O R=1.003)$, and T4 stage $(P=0.007, \quad O R=4.006)$ (Table 12). The Hosmer-Lemeshow test had a $\mathrm{P}$ value of 0.00 , indicating good fit of the data to the model. The AUC of the model was 0.826 (95\% CI: 0.758-0.894) with standard error of 0.035 . Calibration Plot showed that the model expected curve was close to the observed curve, indicating that the model has good predictive capabilities (Supplemental Figure 1B). Subgroup analysis showed that the independent predictor for distant metastasis of colonic MA was T4 stage $(P=0.043, O R=3.627)$ (Table 13). In contrast, none of the examined variables rose to the level of independent predictor for distant metastasis of rectal MA (Table 14).

\section{Discussion}

MA is a unique pathologic entity first described by Parham in $1923 .{ }^{20}$ Compared with colorectal adenocarcinoma, MAC often has a worse prognosis ${ }^{8,21,22}$ and microsatellite instability-high (MSI-H), ${ }^{23}$ and is also more likely to lead to lymphovascular invasion, perineural invasion, ${ }^{4}$ lymph node metastasis, and peritoneal implants. ${ }^{6}$ Considering the particularity of MAC, some researchers believe that patients with MAC may require adjustments in treatment. ${ }^{14}$ Therefore, a thorough evaluation of the predictors of local disease recurrence and distant metastasis of MAC can serve to identify patients with a higher risk of future relapse, and thus improve the individualized management of patients with MAC.

MAC exhibits variation in geographical distribution, accounting for about $5 \%$ of CRC in studies from Asian countries $^{4-6}$ and $10-20 \%$ in studies from Western countries. $^{24-26}$ Consistent with other studies, our data showed that the incidence rate of MAC was $5.24 \%$. 
Table 3 Univariate Analysis of the Risk Factors for Local Recurrence of MAC

\begin{tabular}{|c|c|c|c|c|c|c|}
\hline \multicolumn{2}{|l|}{ Variable (MAC) } & \multirow{2}{*}{$\begin{array}{c}\text { Local Recurrence } \mathbf{N}=\mathbf{3 8} \\
59(15-82)\end{array}$} & \multirow{2}{*}{$\begin{array}{c}\text { No Local Recurrence } \mathbf{N}=\mid \mathbf{2 4} \\
60(24-87)\end{array}$} & \multirow{2}{*}{$\begin{array}{c}95 \% \mathrm{Cl} \\
0.97-1.02\end{array}$} & \multirow{2}{*}{$\frac{O R}{0.992}$} & \multirow{2}{*}{$\frac{P \text {-value }}{0.510}$} \\
\hline Age & Median (range) & & & & & \\
\hline Gender & Male/Female & $19 / 19$ & $67 / 57$ & $0.4 I-1.76$ & 0.851 & 0.663 \\
\hline Comorbidities (\%) & Yes & $14(36.8)$ & $47(37.9)$ & $0.45-2.03$ & 0.956 & 0.906 \\
\hline ASA score & $\begin{array}{l}\mathrm{I}(\mathrm{R}) \\
\text { II } \\
\text { III }\end{array}$ & $\begin{array}{c}16(42.1) \\
20(52.6) \\
2(5.3)\end{array}$ & $\begin{array}{l}57(46.0) \\
48(38.7) \\
19(15.3)\end{array}$ & $\begin{array}{c}- \\
0.69-3.18 \\
0.08-1.78\end{array}$ & $\begin{array}{c}- \\
1.484 \\
0.375\end{array}$ & 0.180 \\
\hline CAI99 (U/mL) & Mean $\pm S D$ & $65.6 \pm 127$ & $55.1 \pm 160$ & $0.998-1.003$ & 1.000 & 0.709 \\
\hline CEA $(\mathrm{ng} / \mathrm{mL})$ & Mean $\pm S D$ & $15.3 \pm 32.5$ & $16.2 \pm 44.7$ & $0.99-1.008$ & 0.999 & 0.908 \\
\hline Tumor location & Colonic/Rectal & $26 / 12$ & $88 / 36$ & $0.5 I-2.48$ & I.I28 & 0.764 \\
\hline Tumor size $(\mathrm{cm})$ & Mean $\pm S D$ & $4.1 \pm 1.7$ & $4.5 \pm 2.2$ & $0.75-1.09$ & 0.907 & 0.305 \\
\hline LAP and OPEN & & $|7 / 2|$ & $66 / 58$ & $0.34-1.48$ & 0.711 & $0.36 \mathrm{I}$ \\
\hline Operative time (min) & Mean \pm SD & $213.9 \pm 80.2$ & $210.12 \pm 78.06$ & $0.996-1.005$ & 1.001 & 0.795 \\
\hline Blood loss (mL) & Mean $\pm S D$ & $178.7 \pm 138.5$ & $116 \pm 93$ & $1.00-1.01$ & 1.005 & $0.004 *$ \\
\hline Transfusion (\%) & Yes & $10(26.3)$ & $8(6.5)$ & $1.87-14.32$ & 5.179 & $0.002 *$ \\
\hline Multivisceral resection (\%) & Yes & $2(5.3)$ & $12(9.7)$ & $0.11-2.43$ & 0.519 & 0.404 \\
\hline Complications (\%) & Yes & $7(18.4)$ & $19(15.3)$ & $0.48-3.24$ & 1.248 & 0.649 \\
\hline Number of LN resected & Median (range) & $15(5-47)$ & $18(6-53)$ & $0.93-1.02$ & 0.973 & 0.205 \\
\hline T stage & $\begin{array}{c}\text { TI-T2 } \\
\text { T3 (R) } \\
\text { T4a+T4b }\end{array}$ & $\begin{array}{c}0 \\
13(34.2) \\
25(65.8)\end{array}$ & $\begin{array}{l}13(10.5) \\
61(49.2) \\
50(40.3)\end{array}$ & $\begin{array}{c}- \\
- \\
1.09-5.05\end{array}$ & $\begin{array}{c}- \\
- \\
2.346\end{array}$ & 0.093 \\
\hline $\mathrm{N}$ stage & $\begin{array}{l}\text { No (R) } \\
\text { NI } \\
\text { N2 }\end{array}$ & $\begin{array}{l}\mathrm{II}(28.9) \\
5(13.2) \\
22(57.9)\end{array}$ & $\begin{array}{l}65(52.4) \\
31(25.0) \\
28(22.6)\end{array}$ & $\begin{array}{c}- \\
0.31-2.98 \\
1.99-10.85\end{array}$ & $\begin{array}{c}- \\
0.953 \\
4.643\end{array}$ & $0.000^{*}$ \\
\hline TNM stage & $\begin{array}{c}\text { I } \\
\text { II(R) } \\
\text { III }\end{array}$ & $\begin{array}{c}0 \\
10(26.3) \\
28(73.7)\end{array}$ & $\begin{array}{c}\text { I I(8.9) } \\
55(44.4) \\
58(46.8)\end{array}$ & $\begin{array}{c}- \\
- \\
1.18-5.97\end{array}$ & $\begin{array}{c}- \\
- \\
2.655\end{array}$ & 0.062 \\
\hline Adjuvant chemotherapy & Yes & $27(7 I . I)$ & $86(69.4)$ & $0.49-2.41$ & 1.085 & 0.842 \\
\hline
\end{tabular}

Previous studies showed that MAC is more frequently found in female patients and is predominantly located in the proximal colon. ${ }^{27-29}$ Our data showed that $42.59 \%$ patients were right colonic MA, which is consistent with previous studies. However, there was one major difference compared to prior work that our data showed the proportion of female patients $(53.09 \%)$ was not dominant.

Over ninety percent of patients $(93 \%)$ had stage II or III disease, in agreement with previous reports showing that MAC is often diagnosed at an advanced stage. ${ }^{30,31}$ There were $91.98 \%$ patients with pathological T3 or T4 stage. More than half of patients $(53.09 \%)$ had lymph node metastasis. A more advanced stage of MAC is attributed to many factors, including the more aggressive nature of MAC compared to colorectal adenocarcinoma and the tendency to form tumors in the proximal colon, which serves to delay clinical symptoms until a more advanced stage has been reached. Perhaps the advanced stage of tumors in this patient cohort contributed to the relatively high rate of cancer recurrence (37.04\%). Our results showed that the five-year DFS rate for stage I tumors was $100 \%$, and DFS rates for stage II and III were $71.2 \%$ and $47.81 \%$, respectively (Figure 2, $P<0.05$ ). Therefore, early and accurate 
Table 4 Subgroup Analysis of the Risk Factors for Local Recurrence of Colonic MA

\begin{tabular}{|c|c|c|c|c|c|c|}
\hline \multicolumn{2}{|l|}{ Variable (Colonic MA) } & \multirow{2}{*}{$\frac{\text { Local Recurrence } \mathbf{N}=\mathbf{2 6}}{60.5(15-82)}$} & \multirow{2}{*}{$\frac{\text { No Local Recurrence } \mathbf{N}=\mathbf{8 8}}{61(24-85)}$} & \multirow{2}{*}{$\begin{array}{c}95 \% \mathrm{Cl} \\
0.96-1.02\end{array}$} & \multirow{2}{*}{$\begin{array}{c}\text { OR } \\
0.991\end{array}$} & \multirow{2}{*}{$\frac{P \text {-value }}{0.508}$} \\
\hline Age & Median (range) & & & & & \\
\hline Gender & Male/Female & $13 / 13$ & $50 / 38$ & $0.32-1.83$ & 0.760 & 0.540 \\
\hline Comorbidities (\%) & Yes & $9(34.6)$ & $36(40.9)$ & $0.31-1.91$ & 0.765 & 0.565 \\
\hline ASA score & $\begin{array}{l}\text { I(R) } \\
\text { II } \\
\text { III }\end{array}$ & $\begin{array}{c}10(38.5) \\
14(53.8) \\
2(7.7)\end{array}$ & $\begin{array}{l}38(43.2) \\
36(40.9) \\
14(15.9)\end{array}$ & $\begin{array}{c}- \\
0.58-3.75 \\
0.11-2.79\end{array}$ & $\begin{array}{c}- \\
1.478 \\
0.543\end{array}$ & 0.412 \\
\hline CAI99 (U/mL) & Mean \pm SD & $75.3 \pm 150.1$ & $60.5 \pm 182.6$ & $0.998-1.003$ & 1.000 & 0.706 \\
\hline CEA (ng/mL) & Mean $\pm S D$ & $18.5 \pm 38.7$ & $|7 \pm 4|$ & $0.99-1.01$ & 1.001 & 0.868 \\
\hline Tumor location & Right/Left & $14 / 12$ & $55 / 33$ & $0.59-3.46$ & 1.429 & 0.429 \\
\hline Tumor size $(\mathrm{cm})$ & Mean $\pm S D$ & $4.2 \pm 1.7$ & $4.9 \pm 2.2$ & $0.66-1.06$ & 0.837 & 0.137 \\
\hline LAP and OPEN & & $11 / 15$ & $45 / 43$ & $0.29-1.7$ & 0.701 & 0.430 \\
\hline Operative time (min) & Mean $\pm S D$ & $202.7 \pm 54.6$ & $199.3 \pm 67.3$ & $0.99-1.01$ & 1.001 & 0.813 \\
\hline Blood loss (mL) & Mean $\pm S D$ & $181.5 \pm 135$ & $112.6 \pm 87.1$ & $1.00-1.01$ & 1.006 & $0.008^{*}$ \\
\hline Transfusion (\%) & Yes & $5(19.2)$ & $5(5.7)$ & $1.05-14.93$ & 3.952 & $0.043 *$ \\
\hline Multivisceral resection (\%) & Yes & $\mathrm{I}(3.8)$ & $\mathrm{II}(\mathrm{I} 2.5)$ & $0.03-2.28$ & 0.280 & 0.234 \\
\hline Complications (\%) & Yes & $5(19.2)$ & $13(14.8)$ & $0.44-4.29$ & $\mathrm{I} .374$ & 0.585 \\
\hline Number of $L N$ resected & Median (range) & $16.5(7-47)$ & $18(6-53)$ & $0.94-1.03$ & 0.985 & 0.510 \\
\hline T stage & $\begin{array}{c}\text { TI-T2 } \\
\text { T3 (R) } \\
\text { T4a+T4b }\end{array}$ & $\begin{array}{c}0 \\
7(26.9) \\
19(73.1)\end{array}$ & $\begin{array}{c}7(8.0) \\
47(53.4) \\
34(38.6)\end{array}$ & $\begin{array}{c}- \\
- \\
1.42-9.92\end{array}$ & $\begin{array}{c}- \\
- \\
3.752\end{array}$ & $0.029 *$ \\
\hline $\mathrm{N}$ stage & $\begin{array}{l}\text { No (R) } \\
\text { NI } \\
\text { N2 }\end{array}$ & $\begin{array}{l}8(30.8) \\
4(15.4) \\
14(53.8)\end{array}$ & $\begin{array}{l}49(55.7) \\
22(25.0) \\
17(19.3)\end{array}$ & $\begin{array}{c}- \\
0.3 \mid-4.1 \\
|.8-| 4.12\end{array}$ & $\begin{array}{c}- \\
\mathrm{I} . \mathrm{II} 4 \\
5.044\end{array}$ & $0.004 *$ \\
\hline TNM stage & $\begin{array}{c}\text { I } \\
\text { II(R) } \\
\text { III }\end{array}$ & $\begin{array}{c}0 \\
7(26.9) \\
19(73.1)\end{array}$ & $\begin{array}{c}7(7.9) \\
43(48.9) \\
38(43.2)\end{array}$ & $\begin{array}{c}- \\
- \\
1.16-8.1\end{array}$ & $\begin{array}{c}- \\
- \\
3.071\end{array}$ & 0.077 \\
\hline Adjuvant chemotherapy & Yes & $20(76.9)$ & $58(65.9)$ & $0.63-4.75$ & $\mathrm{I} .724$ & 0.292 \\
\hline
\end{tabular}

diagnosis plays a critical role in the prevention and treatment of MAC.

The method of surgery did not affect the prognosis of MAC. Our previous study showed that laparoscopic and open surgery for MAC had similar prognoses. ${ }^{19}$ There were many stage $\mathrm{T} 4 \mathrm{~b}$ tumors in this group, which led to more radical organ resection, including abdominal wall, small bowel urinary organs, gynecologic organs, and gallbladder. The rate of postoperative complications (16.05\%) in this group was lower compared with previous reports, ${ }^{31}$ and most of them were mild complications according to the Clavien-Dindo scale. Studies have shown that postoperative complications can affect the prognosis of CRC patients. ${ }^{32}$ However, our results showed that postoperative complications did not influence the prognosis of MAC.

The clinicopathological significance of a mucinous CRC subtype is well appreciated but remains controversial. Some studies have shown that MA has a worse prognosis than non-mucinous adenocarcinoma, ${ }^{11,33,34}$ whereas others have shown no prognostic difference compared to conventional CRC. ${ }^{35,36}$ Although there was no direct comparison with non-mucinous adenocarcinoma in the present study, compared with previous published data, ${ }^{37}$ the 5 -year 
Table 5 Subgroup Analysis of the Risk Factors for Local Recurrence of Rectal MA

\begin{tabular}{|c|c|c|c|c|c|c|}
\hline \multicolumn{2}{|l|}{ Variable (Rectal MA) } & \multirow{2}{*}{$\begin{array}{c}\text { Local Recurrence } \mathbf{N}=\mathbf{~} \mathbf{2} \\
55(43-78)\end{array}$} & \multirow{2}{*}{$\begin{array}{c}\text { No Local Recurrence } \mathbf{N}=\mathbf{3 6} \\
57(29-87)\end{array}$} & \multirow{2}{*}{$\frac{95 \% \mathrm{Cl}}{0.95-1.05}$} & \multirow{2}{*}{$\begin{array}{c}\text { OR } \\
0.996\end{array}$} & \multirow{2}{*}{$\frac{P \text {-value }}{0.882}$} \\
\hline Age & Median (range) & & & & & \\
\hline Gender & Male/Female & $6 / 6$ & $17 / 19$ & $0.3-4.13$ & 1.118 & 0.868 \\
\hline Comorbidities (\%) & Yes & $5(41.7)$ & II (30.6) & $0.42-6.26$ & 1.623 & 0.481 \\
\hline \multirow[t]{3}{*}{ ASA score } & $\mathrm{I}(\mathrm{R})$ & $6(50.0)$ & $19(52.8)$ & - & - & 0.799 \\
\hline & II & $6(50.0)$ & $12(33.3)$ & $0.4 I-6.06$ & 1.583 & \\
\hline & III & $0(0)$ & $5(13.9)$ & - & - & \\
\hline CAI99 (U/mL) & Mean $\pm S D$ & $44.8 \pm 48.3$ & $41.8 \pm 82.9$ & $0.99-1.01$ & 1.001 & 0.906 \\
\hline CEA (ng/mL) & Mean $\pm S D$ & $8.6 \pm 7.7$ & $14.4 \pm 53.5$ & $0.98-1.02$ & 0.996 & 0.719 \\
\hline Tumor size $(\mathrm{cm})$ & Mean $\pm S D$ & $3.8 \pm 1.6$ & $3.3 \pm 1.6$ & $0.79-1.78$ & 1.184 & 0.417 \\
\hline LAP and OPEN & & $6 / 6$ & $21 / 15$ & $0.19-2.65$ & 0.714 & 0.615 \\
\hline Operative time $(\min )$ & Mean $\pm S D$ & $238.2 \pm 118$ & $236.6 \pm 95.5$ & $0.99-1.01$ & 1.000 & 0.962 \\
\hline Blood loss (mL) & Mean $\pm S D$ & $|72.5 \pm| 5 \mid .8$ & $124.4 \pm 106.9$ & $1.00-1.01$ & 1.003 & 0.242 \\
\hline Transfusion (\%) & Yes & $5(41.7)$ & $3(8.3)$ & $\mid .51-40.81$ & 7.857 & $0.014 *$ \\
\hline Multivisceral resection (\%) & Yes & $\mathrm{I}(8.3)$ & $\mathrm{I}(2.8)$ & $0.18-55.19$ & 3.182 & 0.427 \\
\hline Complications (\%) & Yes & $2(16.7)$ & $6(16.7)$ & $0.17-5.77$ & 1.0 & 1.0 \\
\hline Number of LN resected & Median (range) & $13(5-30)$ & $17.5(7-44)$ & $0.85-1.03$ & 0.935 & 0.172 \\
\hline \multirow[t]{3}{*}{ T stage } & TI-T2 & 0 & $6(16.7)$ & - & - & $0.98 I$ \\
\hline & T3 (R) & $6(50.0)$ & 14(38.9) & - & - & \\
\hline & $\mathrm{T} 4 \mathrm{a}+\mathrm{T} 4 \mathrm{~b}$ & $6(50.0)$ & $16(44.4)$ & $0.23-3.34$ & 0.875 & \\
\hline \multirow[t]{3}{*}{$\mathrm{N}$ stage } & No (R) & $3(25.0)$ & $16(44.0)$ & - & - & 0.102 \\
\hline & NI & $\mathrm{I}(8.3)$ & $9(25.0)$ & $0.05-6.57$ & 0.593 & \\
\hline & N2 & $8(66.7)$ & II(30.6) & $0.84-17.97$ & 3.879 & \\
\hline \multirow[t]{3}{*}{ TNM stage } & 1 & 0 & $4(11.1)$ & - & - & 0.742 \\
\hline & $I I(R)$ & $3(25.0)$ & $12(33.3)$ & - & - & \\
\hline & III & $9(75.0)$ & $20(69.0)$ & $0.4 I-7.99$ & 1.8 & \\
\hline Adjuvant chemotherapy & Yes & $7(58.3)$ & $28(77.8)$ & $0.1-1.61$ & 0.4 & 0.197 \\
\hline
\end{tabular}

Note: $* P<0.05$.

Abbreviations: ASA, American Society of Anesthesiology; CAI99, carbohydrate antigen 199; CEA, carcinoembryonic antigen; OR, risk ratio; R, reference group; LAP, laparoscopic surgery group; OPEN, open surgery group; LN, lymph nodes.

OS rate of this group (67.3\%) of mucinous adenocarcinoma was lower. We therefore believe that MAC has a worse prognosis.

The present study aimed to explore the predictors for local recurrence and distant metastasis of MAC after surgery. We found that the local recurrence of MAC mainly manifested as recurrent masses and peritoneal nodules. The independent risk factors for local metastasis were N2 stage and intraoperative transfusion. Patients with N2 stage in this group had higher pathological stages, which suggests that this high-recurrence group should receive extra attention in the process of treating MAC. The independent predictor for local recurrence of MAC was intraoperative transfusion, which has important clinical significance. We know that intraoperative blood transfusion is often caused by excessive intraoperative bleeding. So we think that the main reasons behind this may be as follows. First, more intraoperative bleeding and transfusion may be caused by the higher $\mathrm{T}$ stage and the associated clinical infiltrative growth, leading to difficulty in tumor resection and surgical separation of tumor. These difficulties may have resulted in residual viable tumor 
Table 6 Univariate Analysis of the Risk Factors for Local Distant Metastasis of MAC

\begin{tabular}{|c|c|c|c|c|c|c|}
\hline \multicolumn{2}{|l|}{ Variable (MAC) } & \multirow{2}{*}{$\frac{\text { Distant Metastasis } \mathbf{N}=\mathbf{3 3}}{6 \mathrm{I}(24-82)}$} & \multirow{2}{*}{$\frac{\text { No Distant Metastasis } \mathbf{N}=129}{60(15-87)}$} & \multirow{2}{*}{$\begin{array}{c}95 \% \mathrm{Cl} \\
0.98-1.04\end{array}$} & \multirow{2}{*}{$\frac{\text { OR }}{1.01}$} & \multirow{2}{*}{$\frac{P \text {-value }}{0.452}$} \\
\hline Age & Median (range) & & & & & \\
\hline Gender & Male/Female & $23 / 10$ & $63 / 66$ & $1.06-5.46$ & 2.41 & $0.035^{*}$ \\
\hline Comorbidities (\%) & Yes & 13(39.4) & $48(37.2)$ & $0.5-2.4$ & 1.097 & 0.817 \\
\hline \multirow[t]{3}{*}{ ASA score } & $\mathrm{I}(\mathrm{R})$ & 13(39.4) & $60(46.5)$ & - & - & 0.438 \\
\hline & $\|$ & $17(5 \mid .2)$ & $5 \mathrm{I}(39.5)$ & $0.68-3.47$ & 1.538 & \\
\hline & III & $3(9.1)$ & $18(14.0)$ & $0.2-3.0$ & 0.769 & \\
\hline CAI99 (U/mL) & Mean $\pm S D$ & $141.9 \pm 244.3$ & $35.9 \pm 109.8$ & $|.0-1.0|$ & 1.004 & $0.011 *$ \\
\hline CEA (ng/mL) & Mean $\pm S D$ & $33.9 \pm 62.2$ & II $.5 \pm 34$ & $1.0-1.02$ & 1.010 & 0.020 \\
\hline Tumor location & Colonic/Rectal & $22 / 11$ & $92 / 37$ & $0.55-2.82$ & 1.243 & 0.602 \\
\hline Tumor size $(\mathrm{cm})$ & Mean \pm SD & $4.3 \pm 2.4$ & $4.4 \pm 2$ & $0.82-1.19$ & 0.991 & 0.928 \\
\hline LAP and OPEN & & $17 / 16$ & $67 / 62$ & $0.4 I-1.87$ & 0.871 & 0.723 \\
\hline Operative time $(\mathrm{min})$ & Mean \pm SD & $225.5 \pm 77.5$ & $207.3 \pm 78.4$ & $1.0-1.01$ & 1.003 & 0.240 \\
\hline Blood loss (mL) & Mean $\pm S D$ & $|7| .2 \pm 117.5$ & $120.4 \pm 103.8$ & $1.00-1.01$ & 1.004 & $0.022 *$ \\
\hline Transfusion (\%) & Yes & $6(18.2)$ & $12(9.3)$ & $0.75-6.29$ & 2.167 & 0.155 \\
\hline Multivisceral resection (\%) & Yes & $3(9.1)$ & $\mathrm{II}(8.5)$ & $0.28-4.09$ & 1.073 & 0.918 \\
\hline Complications (\%) & Yes & $5(15.2)$ & $21(16.3)$ & $0.32-2.65$ & 0.918 & 0.875 \\
\hline Number of LN resected & Median (range) & $19(7-45)$ & $17(5-53)$ & $0.96-1.04$ & 1.001 & 0.973 \\
\hline \multirow[t]{3}{*}{ T stage } & TI-T2 & 0 & $13(10.1)$ & - & - & $0.007^{*}$ \\
\hline & T3 (R) & $8(24.2)$ & $66(51.2)$ & - & - & \\
\hline & $T 4 a+T 4 b$ & $25(75.8)$ & $50(38.8)$ & $|.72-9.9|$ & 4.125 & \\
\hline \multirow[t]{3}{*}{$\mathrm{N}$ stage } & No (R) & $10(30.3)$ & $66(5 \mid .2)$ & - & - & $0.018 *$ \\
\hline & NI & $6(18.2)$ & $30(23.3)$ & $0.44-3.97$ & 1.32 & \\
\hline & N2 & $\mid 7(5 \mid .5)$ & $33(25.6)$ & I.4-8.25 & 3.4 & \\
\hline \multirow[t]{3}{*}{ TNM stage } & 1 & 0 & $\mathrm{II}(8.5)$ & - & - & 0.126 \\
\hline & $\Pi(R)$ & $9(27.3)$ & $56(43.4)$ & - & - & \\
\hline & III & $24(72.7)$ & $62(48.1)$ & $1.03-5.62$ & 2.409 & \\
\hline Adjuvant chemotherapy & Yes & $23(69.7)$ & $90(69.8)$ & $0.43-2.29$ & 0.997 & 0.994 \\
\hline
\end{tabular}

cells. Second, studies have shown that MAC is associated with higher peritoneal metastasis and the cells of mucous tumors have a more aggressive nature. ${ }^{14}$ Intraoperative blood loss may facilitate local transplantation of tumor cells. Third, more intraoperative transfusion may lead to slower perioperative recovery and poor immunity of patients, which may result in more postoperative complications that lead to a delay in the start of chemotherapy. Based on these factors that may lead to poor prognosis, we suggest the following guidelines. First, strictly follow the no-touch concept of surgical oncology and perform resection according to total mesorectal excision (TME) or complete mesocolic excision (CME); this will ensure that the intraoperative operation is conducted carefully with clear surgical levels. Second, if patients with MAC experience excessive intraoperative bleeding, it can be flushed with distilled water in the abdominal cavity; intraperitoneal infusion chemotherapy and hyperthermic perfusion can also be considered. Third, if there is no neoadjuvant radiotherapy for rectal MA patients with excessive intraoperative bleeding, adjuvant radiotherapy can be used after surgery. Fourth, for these patients, adjuvant chemotherapy in combination with targeted drugs, or, if their MSIs are unstable, immunotherapy should be considered. Besides, 
Table 7 Subgroup Analysis of the Risk Factor of Distant Metastasis of Colonic MA

\begin{tabular}{|c|c|c|c|c|c|c|}
\hline \multicolumn{2}{|l|}{ Variable (Colonic MA) } & \multirow{2}{*}{$\frac{\text { Distant Metastasis } \mathbf{N}=\mathbf{2 2}}{67(24-82)}$} & \multirow{2}{*}{$\begin{array}{c}\text { No Distant Metastasis } \mathbf{N}=\mathbf{9 2} \\
60(15-85)\end{array}$} & \multirow{2}{*}{$\begin{array}{c}95 \% \mathrm{Cl} \\
0.99-1.05\end{array}$} & \multirow{2}{*}{$\frac{O R}{1.018}$} & \multirow{2}{*}{$\frac{P \text {-value }}{0.291}$} \\
\hline Age & Median (range) & & & & & \\
\hline Gender & Male/Female & $16 / 6$ & $47 / 45$ & $0.92-7.11$ & 2.553 & 0.073 \\
\hline Comorbidities (\%) & Yes & $9(40.9)$ & $36(39.1)$ & $0.42-2.78$ & 1.077 & 0.878 \\
\hline ASA score & $\begin{array}{l}\text { I(R) } \\
\text { II } \\
\text { III }\end{array}$ & $\begin{array}{c}8(36.4) \\
12(54.5) \\
2(9.1)\end{array}$ & $\begin{array}{l}40(43.6) \\
38(4 \mid .3) \\
14(\mid 5.2)\end{array}$ & $\begin{array}{c}- \\
0.58-4.29 \\
0.14-3.77\end{array}$ & $\begin{array}{c}- \\
1.579 \\
0.7 \mid 4\end{array}$ & 0.504 \\
\hline CAI99 (U/mL) & Mean $\pm S D$ & $165.1 \pm 283.3$ & $39.6 \pm 128.5$ & $1.00-1.01$ & 1.003 & $0.022 *$ \\
\hline CEA $(\mathrm{ng} / \mathrm{mL})$ & Mean $\pm S D$ & $46.5 \pm 73.2$ & $10.3 \pm 22.9$ & $1.01-1.03$ & 1.017 & $0.004 *$ \\
\hline Tumor location & Right/Left & $15 / 7$ & $54 / 38$ & $0.25-1.78$ & 0.663 & 0.415 \\
\hline Tumor size $(\mathrm{cm})$ & Mean $\pm S D$ & $4.8 \pm 2.5$ & $4.7 \pm 2.1$ & $0.8 \mathrm{I}-\mathrm{I} .25$ & 1.009 & 0.932 \\
\hline LAP and OPEN & & $9 / 13$ & $47 / 45$ & $0.26-1.7$ & 0.663 & 0.393 \\
\hline Operative time (min) & Mean $\pm S D$ & $208 \pm 67.0$ & $198.2 \pm 64$ & $1.00-1.01$ & 1.002 & 0.522 \\
\hline Blood loss (mL) & Mean \pm SD & $|47.7 \pm| \mid 3.6$ & $123.7 \pm 101.1$ & $1.00-1.01$ & 1.002 & 0.333 \\
\hline Transfusion (\%) & Yes & $3(13.6)$ & $7(7.6)$ & $0.45-8.1$ & 1.917 & 0.376 \\
\hline Multivisceral resection (\%) & Yes & $2(10.5)$ & $10(10.9)$ & $0.17-4.04$ & 0.820 & 0.807 \\
\hline Complications (\%) & Yes & $4(18.2)$ & $14(15.2)$ & $0.36-4.21$ & 1.238 & 0.732 \\
\hline Number of LN resected & Median (range) & $18.5(7-45)$ & $17(6-53)$ & $0.95-1.05$ & 1.000 & 0.998 \\
\hline T stage & $\begin{array}{c}\text { TI-T2 } \\
\text { T3 (R) } \\
\text { T4a+T4b }\end{array}$ & $\begin{array}{c}0 \\
5(22.7) \\
17(77.3)\end{array}$ & $\begin{array}{c}7(7.6) \\
49(53.3) \\
36(39.1)\end{array}$ & $\begin{array}{c}- \\
- \\
|.56-| 3.7 \mid\end{array}$ & $\begin{array}{c}- \\
- \\
4.628\end{array}$ & $0.022 *$ \\
\hline $\mathrm{N}$ stage & $\begin{array}{l}\text { No (R) } \\
\text { NI } \\
\text { N2 }\end{array}$ & $\begin{array}{l}5(22.7) \\
5(22.7) \\
12(54.5)\end{array}$ & $\begin{array}{l}52(56.5) \\
21(22.8) \\
19(20.7)\end{array}$ & $\begin{array}{c}- \\
0.65-9.45 \\
2.04-21.12\end{array}$ & $\begin{array}{c}- \\
2.476 \\
6.568\end{array}$ & $0.006 *$ \\
\hline TNM stage & $\begin{array}{c}\text { I } \\
\text { II(R) } \\
\text { III }\end{array}$ & $\begin{array}{c}0 \\
4(18.2) \\
\mid 8(8 \mid .8)\end{array}$ & $\begin{array}{c}7(7.6) \\
46(50.0) \\
39(42.4)\end{array}$ & $\begin{array}{c}- \\
- \\
1.66-17.01\end{array}$ & $\begin{array}{c}- \\
- \\
5.308\end{array}$ & $0.019 *$ \\
\hline Adjuvant chemotherapy & Yes & $14(63.6)$ & 64(69.6) & $0.29-2.03$ & 0.766 & 0.592 \\
\hline
\end{tabular}

close postoperative follow-up should be emphasized for these patients.

In the group with distant metastasis, the most common type was liver metastasis, followed by lung metastasis. The independent predictors of distant metastasis of MAC were T4 stage and CA199. For the patients with T4 stage, the tumor may invade local blood vessels, causing tumor cells to enter the blood. We believe that the distant metastasis of MAC is closely related to high levels of tumor markers, which is a sign of tumor cells entering the blood before surgery. In addition, our study showed approximately $70 \%$ of patients did undergo adjuvant therapy but did not benefit from it, neither local or distant control. To address this, clinicians should consider using stronger or more specific adjuvant therapy based on the results of genetic testing, such as adding targeted drugs and immune drugs. Studies have shown that MAC has a higher probability of microsatellite instability (MSI-H). 22.64\% of patients in our study group had tumors with high MSI-H (12/53, only 53 patients were tested for MSI status). Second, it warrants close observation of disease progress and levels of tumor markers after operation, and close follow-ups should be scheduled for all these patients. 
Table 8 Subgroup Analysis of the Risk Factor of Distant Metastasis of Rectal MA

\begin{tabular}{|c|c|c|c|c|c|c|}
\hline \multicolumn{2}{|l|}{ Variable (Rectal MA) } & \multirow{2}{*}{$\frac{\text { Distant Metastasis N= I I }}{56(42-76)}$} & \multirow{2}{*}{$\begin{array}{c}\text { No Distant Metastasis N=37 } \\
57(29-87)\end{array}$} & \multirow{2}{*}{$\begin{array}{c}95 \% \mathrm{Cl} \\
0.95-1.05\end{array}$} & \multirow{2}{*}{$\begin{array}{c}\text { OR } \\
0.994\end{array}$} & \multirow{2}{*}{$\frac{P \text {-value }}{0.804}$} \\
\hline Age & Median (range) & & & & & \\
\hline Gender & Male/Female & $7 / 4$ & $16 / 21$ & $0.57-9.22$ & 2.297 & 0.241 \\
\hline Comorbidities (\%) & Yes & $4(36.4)$ & $12(32.4)$ & $0.29-4.87$ & 1.19 & 0.808 \\
\hline \multirow[t]{3}{*}{ ASA score } & $I(R)$ & $5(45.5)$ & $20(54.1)$ & - & - & 0.826 \\
\hline & II & $5(45.5)$ & $13(35.1)$ & $0.37-6.38$ & 1.538 & \\
\hline & III & $I(9.1)$ & $4(10.8)$ & $0.09-11.03$ & 1.000 & \\
\hline CAI99 (U/mL) & Mean \pm SD & $95.5 \pm 137.8$ & $26.8 \pm 31.9$ & $1.00-1.03$ & 1.013 & $0.050^{*}$ \\
\hline CEA $(\mathrm{ng} / \mathrm{mL})$ & Mean \pm SD & $8.8 \pm 9.5$ & $14.2 \pm 52.7$ & $0.98-1.02$ & 0.996 & 0.743 \\
\hline Tumor size $(\mathrm{cm})$ & Mean \pm SD & $3.4 \pm 2$ & $3.5 \pm 1.5$ & $0.65-1.53$ & 0.994 & 0.977 \\
\hline LAP and OPEN & & $7 / 4$ & $20 / 17$ & $0.37-5.96$ & 1.487 & 0.575 \\
\hline Operative time (min) & Mean \pm SD & $260.5 \pm 88.3$ & $230.0 \pm 103.7$ & $1.00-1.01$ & 1.003 & 0.382 \\
\hline Blood loss (mL) & Mean \pm SD & $218.2 \pm 115.82$ & || $2.2 \pm|| \mid 1.2$ & $1.00-1.01$ & 1.007 & $0.027^{*}$ \\
\hline Transfusion (\%) & Yes & $3(27.3)$ & $5(13.5)$ & $0.47-12.22$ & 2.400 & 0.292 \\
\hline Multivisceral resection (\%) & Yes & $I(9.1)$ & $I(2.7)$ & $0.21-62.8$ & 3.600 & 0.380 \\
\hline Complications (\%) & Yes & $I(9 . I)$ & $7(18.9)$ & $0.05-3.92$ & 0.429 & 0.453 \\
\hline Number of LN resected & Median (range) & $19(9-24)$ & $15(5-44)$ & $0.93-1.1$ & $\mathrm{I} .007$ & 0.861 \\
\hline \multirow[t]{3}{*}{ T stage } & TI-T2 & 0 & $6(16.2)$ & - & - & 0.309 \\
\hline & $\mathrm{T} 3(\mathrm{R})$ & $3(27.3)$ & $17(45.9)$ & - & - & \\
\hline & $\mathrm{T} 4 \mathrm{a}+\mathrm{T} 4 \mathrm{~b}$ & $8(72.7)$ & I4(37.8) & $0.72-14.57$ & 3.238 & \\
\hline \multirow[t]{3}{*}{$\mathrm{N}$ stage } & No (R) & $5(39.6)$ & I4(37.8) & - & - & 0.579 \\
\hline & $\mathrm{NI}$ & $\mathrm{I}(20.8)$ & $9(24.3)$ & $0.03-3.12$ & 0.311 & \\
\hline & N2 & $5(39.6)$ & $15(37.8)$ & $0.24-4.24$ & 1.000 & \\
\hline \multirow[t]{3}{*}{ TNM stage } & 1 & 0 & $4(10.8)$ & - & - & 0.660 \\
\hline & $\|(\mathrm{R})$ & $5(45.5)$ & $10(27.0)$ & - & - & \\
\hline & III & $6(54.5)$ & $23(62.2)$ & $0.13-2.12$ & 0.522 & \\
\hline Adjuvant chemotherapy & Yes & $9(81.8)$ & $26(70.3)$ & $0.35-10.28$ & 1.904 & 0.454 \\
\hline
\end{tabular}

Note: $* P<0.05$.

Abbreviations: ASA, American Society of Anesthesiology; CAI99, carbohydrate antigen 199; CEA, carcinoembryonic antigen; OR, risk ratio; R, reference group; LAP, laparoscopic surgery group; OPEN, open surgery group; LN, lymph nodes.

Our study showed that male sex was an independent risk factor for distant metastasis. This finding goes against the findings of another study ${ }^{31}$ that reported female sex to

Table 9 Multivariate Analysis of the Significant Independent Predictors for Local Recurrence of MAC

\begin{tabular}{|l|c|c|c|}
\hline Variable (MAC) & $\mathbf{9 5 \%} \mathbf{C l}$ & OR & $\boldsymbol{P}$-value \\
\hline Blood loss (mL) & $1.00-1.01$ & 1.002 & 0.305 \\
Transfusion & $1.07-16.30$ & 4.175 & $0.04^{*}$ \\
N2 stage & $2.13-13.13$ & 5.291 & $0.000^{*}$ \\
\hline
\end{tabular}

be an influential predictor of poor outcome of MAC. In our opinion, there are several reasons that male sex might be a risk factor: men are more likely to engage in unhealthy lifestyles such as consuming alcohol or smoking and also in aggressive strategies to cope with stress in our country. We found that male relapsed patients had a higher rate of smoking and drinking habits in the present study. It also suggests that tumor treatment should involve not only medical treatment, but also primary prevention (healthy diet, healthy lifestyle, etc.), implemented throughout the course of treatment for MAC. In a large multicenter study, 
Table 10 Multivariate Analysis of the Significant Independent Predictors for Local Recurrence of Colonic MA

\begin{tabular}{|l|c|c|c|}
\hline Variable (Colonic MA) & $\mathbf{9 5 \%} \mathbf{C l}$ & OR & P-value \\
\hline Blood loss (mL) & $1.00-1.01$ & 1.005 & 0.124 \\
Transfusion & $0.09-8.97$ & 0.914 & 0.939 \\
T4 stage & $0.95-7.81$ & 2.729 & 0.061 \\
NI stage & $0.26-4.12$ & 1.033 & 0.963 \\
N2 stage & $1.15-11.27$ & 3.592 & $0.028^{*}$ \\
\hline
\end{tabular}

Table I I Multivariate Analysis of the Significant Independent Predictors for Local Recurrence of Rectal MA

\begin{tabular}{|l|c|c|c|}
\hline Variable (Rectal MA) & $95 \% \mathbf{C I}$ & $O R$ & $P$-value \\
\hline Transfusion & $1.51-40.81$ & 7.857 & $0.014^{*}$ \\
\hline
\end{tabular}

Table 12 Multivariate Analysis of the Significant Independent Predictors for Distant Metastasis of MAC

\begin{tabular}{|l|c|c|c|}
\hline Variable (MAC) & $95 \%$ Cl & OR & $P$-value \\
\hline Male sex & $1.01-6.88$ & 2.63 & $0.049 *$ \\
CAI99 $(\mathrm{U} / \mathrm{mL})$ & $1.00-1.01$ & 1.003 & $0.02^{*}$ \\
CEA $(\mathrm{ng} / \mathrm{mL})$ & $1.00-1.02$ & 1.005 & 0.322 \\
Blood loss $(\mathrm{mL})$ & $1.00-1.01$ & 1.004 & 0.053 \\
T4 stage & $1.47-10.94$ & $4.006^{*}$ & $0.007^{*}$ \\
NI stage & $0.22-3.19$ & 0.832 & 0.789 \\
N2 stage & $0.79-5.73$ & 2.13 & 0.134 \\
\hline
\end{tabular}

Notes: $* P<0.05$. The risk ratio $(\mathrm{OR})$ of $\mathrm{T} 4$ stage is relative to $\mathrm{T} 3$ stage. The risk ratio (OR) of $\mathrm{NI}$ or $\mathrm{N} 2$ stage is relative to N0 stage.

Abbreviations: CAI99, carbohydrate antigen 199; CEA, carcinoembryonic antigen; $\mathrm{OR}$, risk ratio; $\mathrm{Cl}$, confidence interval.

Table I3 Multivariate Analysis of the Significant Independent Predictors for Distant Metastasis of Colonic MA

\begin{tabular}{|l|c|c|c|}
\hline Variable (Colonic MA) & $95 \% \mathrm{Cl}$ & OR & P-value \\
\hline CAI99 $(\mathrm{U} / \mathrm{mL})$ & $1.00-1.01$ & 1.002 & 0.273 \\
CEA $(\mathrm{ng} / \mathrm{mL})$ & $1.00-1.03$ & 1.013 & 0.113 \\
T4 stage & $1.04-12.66$ & $3.627^{*}$ & $0.043^{*}$ \\
N stage & - & - & 0.41 \\
TNM stage & - & - & 0.999 \\
\hline
\end{tabular}

Table 14 Multivariate Analysis of the Significant Independent Predictors for Distant Metastasis of Rectal MA

\begin{tabular}{|l|c|c|c|}
\hline Variable (Rectal MA) & $95 \% \mathrm{CI}$ & OR & $\boldsymbol{P}$-value \\
\hline CA199 (U/mL) & $1.00-1.03$ & 1.011 & 0.11 \\
Blood loss $(\mathrm{mL})$ & $1.00-1.01$ & 1.006 & 0.091 \\
\hline
\end{tabular}

$* P<0.05$. The risk ratio $(\mathrm{OR})$ of $\mathrm{T} 4$ stage is relative to $\mathrm{T} 3$ stage. The risk ratio (OR) of $\mathrm{NI}$ or N2 stage is relative to N0 stage.

Abbreviations: CA199, carbohydrate antigen 199; CEA, carcinoembryonic antigen; $\mathrm{OR}$, risk ratio; $\mathrm{Cl}$, confidence interval. patients with CRC who followed a healthy lifestyle were more likely to survive. ${ }^{38}$ The review also suggests that we should also attach importance to the factors for primary prevention after treatment of CRC. ${ }^{39}$

This study has limitations. The limitations of the present study include the small patients size and its retrospective nature. Large-scale studies and multicenter studies are needed for more extensive analyses.

\section{Conclusions}

In summary, the present study revealed significant predictors for local recurrence and distant metastasis in MAC. Unlike previous studies, we specifically analyzed the surgery-related risk factors for recurrence. Interestingly, the risk factors that predicted local recurrence and distant metastasis of MAC were available before adjuvant treatment. Our results can provide a basis for well-directed and timely follow-up treatment of MAC.

\section{Abbreviations}

CRC, colorectal cancer; MA, mucinous adenocarcinoma; MAC, mucinous colorectal adenocarcinoma; DFS, disease-free survival; AJCC, American Joint Committee on Cancer; UICC, Union for International Cancer Control; NCCN, National Comprehensive Cancer Network; CME, complete mesocolic excision; CA199, carbohydrate antigen 199; CEA, carcinoembryonic antigen; MSI, microsatellite instability; MMR, mismatch repair; ASA, American Society of Anesthesiology; CA199, carbohydrate antigen 199; CEA, carcinoembryonic antigen; OR, risk ratio; LAP, laparoscopic surgery group; OPEN, open surgery group; LN, lymph nodes.

\section{Ethics Approval}

The study was approved by the Ethics Committee of Guangzhou First People's Hospital. This study was conducted in accordance with the Declaration of Helsinki. Because of the retrospective nature of the study, the data were anonymous and the requirement for informed consent was waived.

\section{Author Contributions}

All authors made substantial contributions to conception and design, acquisition of data, or analysis and interpretation of data; took part in drafting the article or revising it critically for important intellectual content; agreed to submit to the current journal; gave final approval of the 
version to be published; and agree to be accountable for all aspects of the work.

\section{Funding}

This research is supported by Medical Science and Technology Research Fund Project of Guangdong (A2019526), National Natural Science Foundation of China (81871943), Natural Science Foundation of Guangdong Province (2017A030311035), Guangzhou Planned Project of Science and Technology (202102010024) .

\section{Disclosure}

The authors report no conflicts of interest for this work.

\section{References}

1. Siegel RL, Miller KD, Goding SA, et al. Colorectal cancer statistics, 2020. CA Cancer J Clin. 2020;70(3):145-164. doi:10.3322/caac.21 601

2. Sung H, Ferlay J, Siegel RL, et al. Global cancer statistics 2020: GLOBOCAN estimates of incidence and mortality worldwide for 36 cancers in 185 countries. CA Cancer J Clin. 2021;71(3):209-249. doi: $10.3322 /$ caac. 21660

3. Hamilton SRBFBP. WHO Classification of Tumours of the Digestive System. 4th ed. Lyon: IARC Press; 2010.

4. Li C, Zheng H, Jia H, et al. Prognosis of three histological subtypes of colorectal adenocarcinoma: a retrospective analysis of 8005 Chinese patients. Cancer Med. 2019;8(7):3411-3419. doi:10.1002/ cam4.2234

5. Yamaguchi T, Taniguchi H, Fujita S, et al. Clinicopathological characteristics and prognostic factors of advanced colorectal mucinous adenocarcinoma. Histopathology. 2012;61(2):162-169. doi:10.1111/ j.1365-2559.2012.04235.x

6. Park JS, Huh JW, Park YA, et al. Prognostic comparison between mucinous and nonmucinous adenocarcinoma in colorectal cancer Medicine (Baltimore). 2015;94(15):e658. doi:10.1097/MD.0000000 000000658

7. Hyngstrom JR, Hu CY, Xing Y, et al. Clinicopathology and outcomes for mucinous and signet ring colorectal adenocarcinoma: analysis from the National Cancer Data Base. Ann Surg Oncol. 2012;19 (9):2814-2821. doi:10.1245/s10434-012-2321-7

8. Khan M, Loree JM, Advani SM, et al. Prognostic implications of mucinous differentiation in metastatic colorectal carcinoma can be explained by distinct molecular and clinicopathologic characteristics. Clin Colorectal Cancer. 2018;17(4):e699-e709. doi:10.1016/j. clcc.2018.07.005

9. Maisano R, Azzarello D, Maisano M, et al. Mucinous histology of colon cancer predicts poor outcomes with FOLFOX regimen in metastatic colon cancer. $J$ Chemother. 2012;24(4):212-216. doi:10.1179/1973947812Y.0000000013

10. Mekenkamp LJ, Heesterbeek KJ, Koopman M, et al. Mucinous adenocarcinomas: poor prognosis in metastatic colorectal cancer. Eur J Cancer. 2012;48(4):501-509. doi:10.1016/j.ejca.2011.12.004

11. Kim SH, Shin SJ, Lee KY, et al. Prognostic value of mucinous histology depends on microsatellite instability status in patients with stage III colon cancer treated with adjuvant FOLFOX chemotherapy: a retrospective cohort study. Ann Surg Oncol. 2013;20 (11):3407-3413. doi:10.1245/s10434-013-3169-1
12. Hashiguchi Y, Muro K, Saito Y, et al. Japanese Society for Cancer of the Colon and Rectum (JSCCR) guidelines 2019 for the treatment of colorectal cancer. Int J Clin Oncol. 2020;25(1):1-42.

13. China NHCO. [Chinese protocol of diagnosis and treatment of colorectal cancer (2020 edition)]. Zhonghua Wai Ke Za Zhi. 2020;58 (8):561-585. doi:10.3760/cma.j.cn112139-20200518-00390

14. Hugen N, Brown G, Glynne-Jones R, de Wilt JH, Nagtegaal ID. Advances in the care of patients with mucinous colorectal cancer. Nat Rev Clin Oncol. 2016;13(6):361-369. doi:10.1038/nrclinonc. 2015.140

15. Edge SRBC SB. AJCC Cancer Staging Manual. 7th ed. New York: Springer-Verlag; 2010.

16. Greene FL, American Joint Committee on Cancer, American Cancer Society. AJCC Cancer Staging Manual. 6th ed. New York: Springer; 2002.

17. Hohenberger W, Weber K, Matzel K, Papadopoulos T, Merkel S. Standardized surgery for colonic cancer: complete mesocolic excision and central ligation-technical notes and outcome. Colorectal Dis. 2009;11(4):354-364， 364-365. doi:10.1111/j.1463-1318.20 08.01735.x

18. Heald RJ. The 'Holy Plane' of rectal surgery. $J$ R Soc Med. 1988;81 (9):503-508. doi:10.1177/014107688808100904

19. Huang Q, Zou MH, Jiang Y, et al. Outcomes of laparoscopic surgery for mucinous colorectal adenocarcinoma. J Laparoendosc Adv Surg Tech A. 2020. doi:10.1089/lap.2020.0588

20. Parham D. Colloid Carcinoma. Ann Surg. 1923;77(1):90-105.

21. Li ZP, Liu XY, Kao XM, et al. Clinicopathological characteristics and prognosis of colorectal mucinous adenocarcinoma and nonmucinous adenocarcinoma: a surveillance, epidemiology, and end results (SEER) population-based study. Ann Transl Med. 2020;8(5):205. doi:10.21037/atm.2020.01.52

22. Yu F, Huang L, Shen F, Wu S, Chen J. Prognostic implications of mucinous histology in stage III colon cancer with the receipt of adjuvant chemotherapy. $J$ Gastrointest Oncol. 2020;11(5):858-869. doi:10.21037/jgo-20-160

23. Andrici J, Farzin M, Sioson L, et al. Mismatch repair deficiency as a prognostic factor in mucinous colorectal cancer. Mod Pathol. 2016;29 (3):266-274. doi:10.1038/modpathol.2015.159

24. Williams DS, Mouradov D, Newman MR, et al. Tumour infiltrating lymphocyte status is superior to histological grade, DNA mismatch repair and BRAF mutation for prognosis of colorectal adenocarcinomas with mucinous differentiation. Mod Pathol. 2020;33(7):14201432. doi:10.1038/s41379-020-0496-1

25. Catalano V, Loupakis F, Graziano F, et al. Prognosis of mucinous histology for patients with radically resected stage II and III colon cancer. Ann Oncol. 2012;23(1):135-141. doi:10.1093/annonc/mdr062

26. Fields AC, Lu P, Goldberg J, Irani J, Bleday R, Melnitchouk N. The role of adjuvant chemotherapy in stage II and III mucinous colon cancer. J Surg Oncol. 2019;120(7):1190-1200. doi:10.1002/jso.25705

27. Hugen N, Verhoeven RH, Radema SA, et al. Prognosis and value of adjuvant chemotherapy in stage III mucinous colorectal carcinoma. Ann Oncol. 2013;24(11):2819-2824. doi:10.1093/annonc/mdt378

28. Wang L, Hirano Y, Heng G, et al. Mucinous adenocarcinoma as a high-risk factor in stage ii colorectal cancer: a propensity scorematched study from Japan. Anticancer Res. 2020;40(3):1651-1659. doi:10.21873/anticanres.14115

29. Ott C, Gerken M, Hirsch D, et al. Advanced mucinous colorectal cancer: epidemiology, prognosis and efficacy of chemotherapeutic treatment. Digestion. 2018;98(3):143-152. doi:10.1159/000487710

30. Hugen N, van Beek JJ, de Wilt JH, Nagtegaal ID. Insight into mucinous colorectal carcinoma: clues from etiology. Ann Surg Oncol. 2014;21(9):2963-2970. doi:10.1245/s10434-014-3706-6

31. Emile SH, Magdy A, Elnahas W, Hamdy O, Abdelnaby M, Khafagy W. Predictors for local recurrence and distant metastasis of mucinous colorectal adenocarcinoma. Surgery. 2018;164(1):56-65. doi:10.10 16/j.surg.2017.11.028 
32. Aoyama T, Oba K, Honda M, et al. Impact of postoperative complications on the colorectal cancer survival and recurrence: analyses of pooled individual patients' data from three large Phase III randomized trials. Cancer Med. 2017;6(7):1573-1580. doi:10.1002/ cam4.1126

33. Catalano V, Loupakis F, Graziano F, et al. Mucinous histology predicts for poor response rate and overall survival of patients with colorectal cancer and treated with first-line oxaliplatin- and/or irinotecan-based chemotherapy. $\mathrm{Br} J$ Cancer. 2009;100(6):881-887. doi:10.1038/sj.bjc.6604955

34. Bagante F, Spolverato G, Beal E, et al. Impact of histological subtype on the prognosis of patients undergoing surgery for colon cancer. $J$ Surg Oncol. 2018;117(7):1355-1363. doi:10.1002/jso.25044

35. Gonzalez RS, Cates J, Washington K. Associations among histological characteristics and patient outcomes in colorectal carcinoma with a mucinous component. Histopathology. 2019;74(3):406-414. doi:10.1111/his. 13748

36. Hugen N, van de Velde CJ, Bosch SL, et al. Modern treatment of rectal cancer closes the gap between common adenocarcinoma and mucinous carcinoma. Ann Surg Oncol. 2015;22(8):2669-2676. doi:10.1245/s10434-014-4339-5
37. Allemani C, Matsuda T, Di Carlo V, et al. Global surveillance of trends in cancer survival 2000-14 (CONCORD-3): analysis of individual records for 37513025 patients diagnosed with one of 18 cancers from 322 population-based registries in 71 countries. Lancet. 2018;391(10125):1023-1075.

38. Van Blarigan EL, Fuchs CS, Niedzwiecki D, et al. Association of survival with adherence to the american cancer society nutrition and physical activity guidelines for cancer survivors after colon cancer diagnosis: the CALGB 89803/Alliance Trial. JAMA Oncol. 2018;4 (6):783-790. doi:10.1001/jamaoncol.2018.0126

39. Dekker E, Tanis PJ, Vleugels J, Kasi PM, Wallace MB. Colorectal cancer. Lancet. 2019;394(10207):1467-1480. doi:10.1016/S01406736(19)32319-0

\section{Publish your work in this journal}

Cancer Management and Research is an international, peer-reviewed open access journal focusing on cancer research and the optimal use of preventative and integrated treatment interventions to achieve improved outcomes, enhanced survival and quality of life for the cancer patient.
The manuscript management system is completely online and includes a very quick and fair peer-review system, which is all easy to use. Visit http://www.dovepress.com/testimonials.php to read real quotes from published authors. 